\title{
Comparative Assessment of Genetic Diversity of Peanut (Arachis hypogaea L.) Genotypes with Various Levels of Re- sistance to Bacterial Wilt Through SSR and AFLP Analyses
}

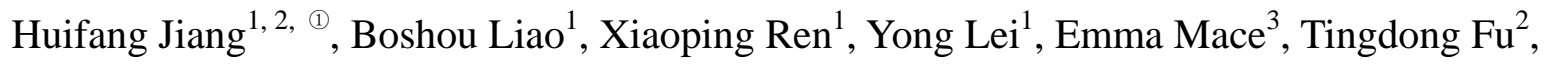 \\ J. H. Crouch ${ }^{3}$ \\ 1. Oil Crops Research Institute, Chinese Academy of Agricultural Sciences, Wuhan 430062, China; \\ 2. College of Plant Science and Technology of Huazhong Agricultural University, Wuhan 430070, China; \\ 3. International Crops Research Institute for the Semi-Arid Tropics, Patancheru, A. P. 502324, India
}

\begin{abstract}
Bacterial wilt (BW) caused by Ralstonia solanacearum is an important constraint to peanut (Arachis hypogaea L.) production in several Asian and African countries, and planting BW-resistant cultivars is the most feasible method for controlling the disease. Although several BW-resistant peanut germplasm accessions have been identified, the genetic diversity among these has not been properly investigated, which has impeded efficient utilization. In this study, the genetic relationships of 31 peanut genotypes with various levels of resistance to BW were assessed based on SSR and AFLP analyses. Twenty-nine of 78 SSR primers and 32 of 126 AFLP primer combinations employed in this study were polymorphic amongst the peanut genotypes tested. The SSR primers amplified 91 polymorphic loci in total with an average of 3.14 alleles per primer, and the AFLP primers amplified 72 polymorphic loci in total with an average of 2.25 alleles per primer. Four SSR primers (14H06, 7G02, 3A8, 16C6) and one AFLP primer (P1M62) were found to be most efficient in detecting diversity. The genetic distance between pairs of genotypes ranged from 0.12 to 0.94 with an average of 0.53 in the SSR data and from 0.06 to 0.57 with an average of 0.25 in the AFLP data. The SSR-based estimates of the genetic distance were generally larger than that based on the AFLP data. The genotypes belonging to subsp. fastigiata possessed wider diversity than that of subsp. hypogaea. The clustering of genotypes based on the SSR and AFLP data were similar but the SSR clustering was more consistent with morphological classification of A. hypogaea. Optimum diverse genotypes of both subsp. hypogaea and subsp. fastigiata can be recommended based on this analysis for developing mapping populations and breeding for high yielding and resistant cultivars.
\end{abstract}

Keywords: peanut; bacterial wilt resistance; genetic diversity; SSR; AFLP

Bacterial wilt (BW) caused by Ralstonia solanacearum E. F. Smith has been the most important bacterial disease affecting peanut or groundnut (Arachis hypogaea L.) production in several countries in Asia including China, Indonesia, and Vietnam and Uganda in Africa ${ }^{[1]}$. It has been estimated that $10 \%$ of peanut fields are infested with the BW pathogen in China, with higher incidencein south and central regions ${ }^{[2,3]}$. With the expansion of peanut production, the disease is expected to become more widespread. As a soil-borne bacterial disease, BW has proven to be difficult to control. Unlike most other diseases affecting peanut, no chemical is available for BW control. Although some cultural approaches such as long-term rotation and soil

Received: 2006-10-23; Accepted: 2006-12-11

This work was supported by the National Natural Science Foundation of China (NSFC) (No. 30070521 and 30270840).

(1) Corresponding author. E-mail: peanutlab@oilcrops.cn; Tel: +86-27-8681 2725 
solarization have been regarded as effective for reducing BW incidence to some extent, these are less applicable in most developing countries where arable land per capita is generally limited. Conversely, host plant resistance has been regarded as the most important component for any integrated approach to control the disease in the farmer's field and BW-resistant cultivars are essential for peanut production in heavily infested fields ${ }^{[1]}$.

New sources of resistance are crucial for developing resistant cultivars in crops. In peanut, there have been several BW resistance screening and breeding activities in China since the $1970 \mathrm{~s}^{[1,3,4]}$. Worldwide, more than 170 accessions across four botanical varieties of cultivated peanut and its related wild species have been identified as BW-resistant ${ }^{[4-6]}$. Among the 5,700 peanut germplasm accessions screened in China, 112 were found to be highly resistant ${ }^{[6,7]}$, about $60 \%$ of which belonged to subsp. hypogaea var. hirsuta, $30 \%$ belonged to subsp. fastigiata var. vulgaris, and $10 \%$ belonged to subsp. hypogaea var. hypogaea and subsp. fastigiata var. fastigiata.

In China, extensive efforts have been made in peanut breeding for BW-resistance and several resistant cultivars have been released ${ }^{[3,5,6]}$. However, these cultivars have relatively low yields with poor resistance or tolerance to other constraints, such as foliar diseases and drought ${ }^{[2-6]}$. Only a few sources of BW-resistance have been successfully used in breeding programs in China even though several resistant genotypes are available ${ }^{[5,6]}$. Most BW-resistant cultivars released in China are based on just three sources of resistance ('Xiekangqing', 'Taishan Sanlirou', or 'Taishan Zhenzhu'), all of which belong to subsp. fastigiata $^{[6]}$. Obviously, the genetic background of parents in breeding programs is still narrow, which may have impeded the progress of breeding. Hence, a better understanding of the genetic diversity amongst the available BW-resistant germplasm is a prerequisite for further efficient improvement of BW resistance.
Several approaches including molecular ${ }^{[8-17]}$ and morphological characterization ${ }^{[18]}$ have been used in assessing the genetic diversity of peanut germplasm. However, this is the first report focusing on peanut germplasm with BW resistance. In the present study, 31 peanut genotypes with various levels of BW resistance were used for a comparative diversity assessment based on SSR (simple sequence repeats) and AFLP (amplified fragment length polymorphism) analyses.

\section{Materials and Methods}

\subsection{Plant materials}

Thirty-one peanut accessions comprising 15 genotypes belonging to subsp. hypogaea var. hirsuta, 2 belonging to var. hypogaea, 13 belonging to subsp. fastigiata var. vulgaris, and 1 belonging to var. fastigiata, were used in this study. Among these, 27 were BW-resistant and 4 were highly susceptible to BW (Table 1).

\subsection{DNA extraction}

Genomic DNA was isolated from young leaves of 15-day-old seedlings. Each sample consisted of leaves pooled from 3-5 seedlings (approximately $2 \mathrm{~g}$ ), and DNA was extracted according to the procedure described by Kochert et al. (1991) ${ }^{[19]}$. The DNA quality was visually checked using $0.8 \%$ agarose gel electrophoresis and quantified at a wavelength of 260 nm using a spectrophotometer.

\subsection{SSR analysis}

Seventy-eight SSR primer pairs (sequence provided by Applied Genomics Laboratory, International Crops Research Institute for the Semi-Arid Tropics, India. Table 2) were used to amplify the genomic DNAs. Polymerase chain reaction (PCR) was carried out in $10 \mu \mathrm{L}$ reaction volume containing $10 \mathrm{ng}$ genomic DNA, $1 \times$ PCR reaction buffer, $2 \mathrm{mmol} / \mathrm{L} \mathrm{Mg}^{2+}$, $0.15 \mathrm{mmol} / \mathrm{L} \mathrm{dNTPs}, 10 \times 10^{-6} \mu \mathrm{mol} / \mathrm{L}$ primers, and 
Table 1 Peanut genotypes used in SSR and AFLP analyses

\begin{tabular}{|c|c|c|c|c|c|}
\hline Entry No. & Genotype & Botanical type & Reaction to $\mathrm{BW}{ }^{\text {a) }}$ & Pedigree & Origin $^{b)}$ \\
\hline 1 & Zhonghua 6 & vulgaris & $\mathrm{R}$ & Breeding line & Hubei \\
\hline 2 & Goulezhong & hypogaea & $\mathrm{R}$ & Landrace & Fujian \\
\hline 3 & Qingmiaodou & hirsuta & $\mathrm{R}$ & Landrace & Guangxi \\
\hline 4 & Zao 18 & vulgaris & $\mathrm{S}$ & Breeding line & Hubei \\
\hline 5 & Daye Bentianzi & hirsuta & $\mathrm{S}$ & Landrace & Jiangxi \\
\hline 6 & Yuanza 9102 & vulgaris & $\mathrm{R}$ & Breeding line & Henan \\
\hline 7 & Yueyou 200 & vulgaris & $\mathrm{R}$ & Breeding line & Guangdong \\
\hline 8 & Xiekangqing & vulgaris & $\mathrm{R}$ & Landrace & Guangdong \\
\hline 9 & Luoao Wanhuasheng & hirsuta & $\mathrm{R}$ & Landrace & Jiangxi \\
\hline 10 & Wuxuan Laohuasheng & hirsuta & $\mathrm{R}$ & Landrace & Guangxi \\
\hline 11 & Zhonghua 2 & vulgaris & $\mathrm{R}$ & Breeding line & Hubei \\
\hline 12 & Changsha Tuzi & hirsuta & $\mathrm{R}$ & Landrace & Hunan \\
\hline 13 & Feilongxiang & hirsuta & $\mathrm{R}$ & Landrace & Guangxi \\
\hline 14 & Shitang Dahuasheng & hirsuta & $\mathrm{R}$ & Landrace & Guangxi \\
\hline 15 & Zhonghua 212 & vulgaris & $\mathrm{R}$ & Breeding line & Hubei \\
\hline 16 & Taishan Zhenzhu & vulgaris & $\mathrm{R}$ & Landrace & Guangdong \\
\hline 17 & Jiangtianzhong & hypogaea & $\mathrm{R}$ & Landrace & Fujian \\
\hline 18 & Qidong Dahusheng & hirsuta & $\mathrm{R}$ & Landrace & Hunan \\
\hline 19 & Nanning Sanjindou & hirsuta & $\mathrm{R}$ & Landrace & Guangxi \\
\hline 20 & Lingui Make & hirsuta & $\mathrm{R}$ & Landrace & Guangxi \\
\hline 21 & Chico & vulgaris & $\mathrm{S}$ & Landrace & ICRISAT \\
\hline 22 & Bobai Dahuasheng & hirsuta & $\mathrm{R}$ & Landrace & Guangxi \\
\hline 23 & Mashan Guling & hirsuta & $\mathrm{R}$ & Landrace & Guangxi \\
\hline 24 & ShengxianXiaohongmao & hirsuta & $\mathrm{R}$ & Landrace & Zhejiang \\
\hline 25 & Ehua 5 & vulgaris & $\mathrm{R}$ & Breeding line & Hubei \\
\hline 26 & Zhongxingchi & hirsuta & $\mathrm{R}$ & Landrace & Fujian \\
\hline 27 & Bobai Shiyaodou & hirsuta & $\mathrm{R}$ & Landrace & Guangxi \\
\hline 28 & Taishan Sanlirou & fastigiata & $\mathrm{R}$ & Landrace & Guangdong \\
\hline 29 & $91-074$ & vulgaris & $\mathrm{R}$ & Breeding line & Hubei \\
\hline 30 & $89-15048$ & vulgaris & $\mathrm{R}$ & Breeding line & Hubei \\
\hline 31 & Zhonghua 5 & vulgaris & $\mathrm{S}$ & Breeding line & Hubei \\
\hline
\end{tabular}

${ }^{\text {a) }} \mathrm{R}=$ population survival ratio over $80 \%$, and $\mathrm{S}=$ population survival ratio less than $50 \%$;

b) All origin places are the province name in China except for ICRISAT.

1.2 U Taq DNA polymerase. The reaction was performed at $94^{\circ} \mathrm{C}$ for $2 \mathrm{~min} ; 35$ cycles of $94^{\circ} \mathrm{C}$ for $45 \mathrm{~s}$, empirically defined annealing temperature $\left(55-60^{\circ} \mathrm{C}\right.$, Table 2) for $1 \mathrm{~min}, 72^{\circ} \mathrm{C}$ for $90 \mathrm{~s}$, then a final extension of $10 \mathrm{~min}$ with $72^{\circ} \mathrm{C}$. The amplified products were visualized on non-denaturing 6\% 29:1 (w/w) polyacrylamide/bisacrylamide gels followed by silver staining as described by Ferguson et al. (2004) ${ }^{[9]}$.

\subsection{AFLP analysis}

AFLP fingerprints were generated based on the protocol of Vos et al. ${ }^{[20]}$ with minor modifications. Genomic DNA (0.6 $\mu \mathrm{g})$ of each sample was digested for $3 \mathrm{~h}$ with Mse I and Pst I followed by overnight ligation at $15^{\circ} \mathrm{C}$ with corresponding adaptors in a total volume of $5 \mu \mathrm{L}$. 
A $5 \mu \mathrm{L}$ mixture of 1:20 dilution of the adaptor-ligated fragments was pre-amplified using corresponding pre-amplification primers in a volume of $20 \mu \mathrm{L}$ for 1 min at $94^{\circ} \mathrm{C}$, then 25 cycles of $30 \mathrm{~s}$ at $94^{\circ} \mathrm{C}, 30 \mathrm{~s}$ at 56 ${ }^{\circ} \mathrm{C}$ and $1 \mathrm{~min}$ at $72^{\circ} \mathrm{C}$, followed by an elongation of 5 $\min$ at $72^{\circ} \mathrm{C}$. Selective amplification reactions were performed in a total of $20 \mu \mathrm{L}$ volume containing $5 \mu \mathrm{L}$ of 1:50 diluted pre-amplification product, $2 \mu \mathrm{L} 10 \times$ polymerase buffer with $\mathrm{Mg}^{2+}, 0.2 \mu \mathrm{L}$ dNTPs with 25 $\mathrm{mmol} / \mathrm{L}, 1 \mu \mathrm{L}$ Mse I -primer $+3(50 \mathrm{ng} / \mu \mathrm{L}), 1 \mu \mathrm{L}$ Pst I -primer + $3(50 \mathrm{ng} / \mu \mathrm{L})$, and $1 \mathrm{U}$ Taq DNA polymerase
(Table 3). The cycling program used for selective amplification was carried out at $94^{\circ} \mathrm{C}$ for 1 min followed by 12 touch down cycles of $30 \mathrm{~s}$ at $94^{\circ} \mathrm{C}, 30 \mathrm{~s}$ at $65^{\circ} \mathrm{C}$, and $1 \mathrm{~min}$ at $72^{\circ} \mathrm{C}$. In which, the annealing temperature was lowered by $0.7^{\circ} \mathrm{C}$ per cycle. The mixture then underwent 22 cycles at $94^{\circ} \mathrm{C}$ for $30 \mathrm{~s}, 56^{\circ} \mathrm{C}$ for $30 \mathrm{~s}$, and $72^{\circ} \mathrm{C}$ for $1 \mathrm{~min}$ followed by an elongation of $5 \mathrm{~min}$ at $72^{\circ} \mathrm{C}$. The AFLP products were separ- ated on $6 \%$ denaturing polyacrylamide gels (29:1 acryl- amide: bisacrylamide with $210 \mathrm{~g}$ of urea) follow ed by silver staining as described by Ferguson et al. (2004) ${ }^{[9]}$.

Table 2 Sequences and alleles number amplified of the polymorphic primers used in SSR analysis

\begin{tabular}{|c|c|c|c|c|}
\hline Primer & 5' Left / Forward / Sense Seq 3' & 5' Right / Reverse / Anti-Sense Seq 3' & $\begin{array}{l}\text { Optimum annealing } \\
\text { temperature }\left({ }^{\circ} \mathrm{C}\right)\end{array}$ & $\begin{array}{l}\text { Number } \\
\text { of alleles }\end{array}$ \\
\hline $2 \mathrm{G} 3$ & ATTCACAAGGGGACAGTTGC & ATTCAAGCCTGGGAAACAGA & 60 & 3 \\
\hline $2 \mathrm{G} 4$ & TTCTTGGTTCCTTTGGCTTC & TGCTCAAGTGTCCTTATTGGTG & 60 & 3 \\
\hline $2 \mathrm{~A} 5$ & GGGAATAGCGAGATACATGTCAG & CAGGAGAGAAGGATTGTGCC & 60 & 3 \\
\hline 2A6 & GCTTCTTCGTTGTTGCCTTC & TGCCAGTTGTTCATAGCTTCA & 60 & 4 \\
\hline $2 \mathrm{~F} 5$ & TGACCAAAGTGATGAAGGGA & AAGTTGTTTGTACATCTGTCATCG & 58 & 4 \\
\hline $2 \mathrm{E} 6$ & TACAGCATTGCCTTCTGGTG & CCTGGGCTGGGGTATTATTT & 60 & 2 \\
\hline 2C11 & TGACCTCAATTTTGGGGAAG & GCCACTATTCATCGCGGTA & 60 & 3 \\
\hline 3A8 & ATACGTGACTTGGGCCAGAC & AGTGAAAAATACACCCAACGAA & 60 & 4 \\
\hline 5D5 & AAAAGAAAGACCTTCCCCGA & GCAGGTAATCTGCCGTGATT & 60 & 3 \\
\hline 8D9 & TGAGTTTCCCCAAAAGGAGA & CAACAACAATACGGCCAACA & 60 & 3 \\
\hline $7 \mathrm{G} 2$ & ACTCCCGATGCACTTGAAAT & AACCTCTGTGCACTGTCCCT & 60 & 4 \\
\hline 8E12 & TCTGTTGAGAACCACCAGCA & GTGCTAGTTGCTTGACGCAC & 60 & 3 \\
\hline $11 \mathrm{H} 1$ & TTTGTGTTTAAGAAGGGGTGC & GCGGTCCAACATCCTTTTT & 60 & 3 \\
\hline $12 \mathrm{~F} 7$ & TGTCGTTGTAAGACCTCGGA & TTGGTTTCCTTAAGGCTTCG & 55 & 2 \\
\hline $13 \mathrm{~A} 10$ & AACTCGCTTGTACCGGCTAA & AGGAATAATAACAATACCAACAGCA & 60 & 3 \\
\hline 13E9 & GGAGGAGGACGACGATGATA & TGTCGTCTCATCCAAAGGAA & 60 & 2 \\
\hline $14 \mathrm{~A} 7$ & GTACGCTTTTAATTTGCGGG & CTGGAAAGCCTTGAGAGCAT & 60 & 2 \\
\hline $14 \mathrm{E} 10$ & ACCTAGTGGGACAAGGCTTTA & TTGACAAAATAACCTCACTTCGAT & 55 & 2 \\
\hline $14 \mathrm{~F} 4$ & ACGTTTAGTTGCTTGCGTGA & TGAATTCAAAGGAAAATGAAAAA & 60 & 3 \\
\hline $14 \mathrm{H} 6$ & GCAACTAGGGTGTATGCCGT & CAACCCTATACACCGAGGGA & 60 & 8 \\
\hline $15 \mathrm{C} 12$ & ACAATGCAATGACCGTTGTT & TTGTTGCATGAGAACGTGAA & 60 & 4 \\
\hline $16 \mathrm{C} 6$ & TTGCTACTAAGCCGAAAATGAAG & CTTGAAATTAACACATATGCACACA & 60 & 4 \\
\hline $16 \mathrm{~F} 10$ & TGGAGGGAAAAACATTTTGG & CCTGGAGGGGTGAGAGGT & 60 & 2 \\
\hline 17E1 & TTCGTTGACGTGAGCGTTAC & TTAGGATTGTTCCAAGGCCA & 60 & 3 \\
\hline $17 \mathrm{~F} 6$ & CGTCGGATTTATCTGCCAGT & AGTAGGGGCAAGGGTTGATG & 58 & 3 \\
\hline $18 \mathrm{C} 5$ & GGACAGCCGGATGCTATTTA & ACATGAGTCCСTTTTCCСTT & 60 & 3 \\
\hline 19A5 & ATTCGTCTCCTTCTTTTGGC & TTTTGCTTCCAAATGGCTTC & 60 & 2 \\
\hline 2D12B & AAGCTGAACGAACTCAAGGC & TGCAATGGGTACAATGCTAGA & 60 & 4 \\
\hline 10H1A & TGACAATGGGGTGTTCTTCA & GTAAACAGACGCCGTTCCAT & 60 & 2 \\
\hline
\end{tabular}


Table 3 Sequences of the polymorphic primers used in AFLP analysis

\begin{tabular}{|c|c|c|c|c|c|c|c|}
\hline Series (P) & Sequences & Series $(\mathrm{P})$ & Sequences & Series (M) & Sequences & Series (M) & Sequences \\
\hline P1 & $\mathrm{P}+\mathrm{AGA}$ & P9 & $\mathrm{P}+\mathrm{GGA}$ & M47 & $\mathrm{M}+\mathrm{CAA}$ & M56 & $\mathrm{M}+\mathrm{CGC}$ \\
\hline $\mathrm{P} 2$ & $\mathrm{P}+\mathrm{AGT}$ & P13 & $\mathrm{P}+\mathrm{TGT}$ & M48 & $\mathrm{M}+\mathrm{CAC}$ & M57 & $\mathrm{M}+\mathrm{CGG}$ \\
\hline P3 & $\mathrm{P}+\mathrm{CAC}$ & & & M51 & $\mathrm{M}+\mathrm{CCA}$ & M58 & $\mathrm{M}+\mathrm{CGT}$ \\
\hline P4 & $\mathrm{P}+\mathrm{CAG}$ & & & M52 & $\mathrm{M}+\mathrm{CCC}$ & M59 & $\mathrm{M}+\mathrm{CTA}$ \\
\hline P5 & $\mathrm{P}+\mathrm{CCA}$ & & & M53 & $\mathrm{M}+\mathrm{CCG}$ & M60 & M+CTC \\
\hline P7 & $\mathrm{P}+\mathrm{GCA}$ & & & M54 & $\mathrm{M}+\mathrm{CCT}$ & M61 & $\mathrm{M}+\mathrm{CTG}$ \\
\hline P8 & $\mathrm{P}+\mathrm{GCT}$ & & & M55 & $\mathrm{M}+\mathrm{CGA}$ & M62 & $\mathrm{M}+\mathrm{CTT}$ \\
\hline
\end{tabular}

P: gac tgc gta cat gca g; M: gat gag tcc tga gta a.

\subsection{Data analysis}

For SSR and AFLP analyses, the amplified bands were scored as present " 1 " and absent " 0 ". Genetic similarity (GS) was calculated as described by Nei and $\mathrm{Li}(1979)^{[21]}$. Genetic distance (GD) was calculated as -ln(GS). Cluster analysis was conducted using the unweighted pair-group method of arithmetic means (UPGMA) based on the GDs.

\section{Results}

\subsection{Diversity based on SSR analysis}

Diversity assessment of the 31 peanut genotypes was performed using 78 SSR primer pairs, of which 29 primers amplified polymorphic bands. A total of 91 polymorphic loci were recorded among the peanut genotypes tested (Table 4). The 29 polymorphic SSR primers each amplified 2 to 8 microsatellite loci, with an average of 3.14 loci per primer. Several primers including 7G02, 14H6, 3A8, and 16C6 were more efficient than the rest in detecting the diversity among peanut genotypes since each amplified 4 to 8 loci.

Based on SSR analysis, the average genetic pairwise distance among the 31 genotypes was 0.53 . The largest distance was 0.94 between 'Wuxuan Laohuasheng' and 'Taishan Zhenzhu' and the shortest distance was 0.12 between 'Feilongxiang' and 'Shitang Dahuasheng'. All these four lines were BW-resistant. Moreover, the 17 most diverse genotype pairs (with genetic distances over 0.8) were all BW-resistant. The distances among the susceptible accessions were relatively smaller, ranging from 0.47 (between 'Zhonghua 5' and 'Zao 18') to 0.55 (between 'Zhonghua 5' and 'Daye Bentianzi'). The average distance between the resistant and susceptible genotypes was 0.54 with the greatest diversity between 'Chico' and 'Zhongxinchi' (0.78). A BW-susceptible line, 'Zhonghua 5' with high yield and high oil content, had an average distance of 0.52 from the resistant genotypes with a range from 0.32 (between 'Zhonghua 5' and 'Shenxian Xiaohongmao') to 0.64 (between 'Zhonghua 5' and 'Lingui Make'). Six genotypes including 'Taishan Zhenzhu', 'Xiekangqing', 'Feilongxiang', 'Shitang Dahuasheng', 'Qidong Dahuasheng', and 'Lingui Make' had distances of over 0.6 in comparison with 'Zhonghua 5'. These results indicate that there is a considerable amount of genetic variation among the peanut genotypes involved, particularly the BW-resistant germplasm.

The cluster analysis using UPGMA based on genetic distances from SSR marker analysis revealed that the 31 genotypes can be divided into 2 groups at a genetic distance of 0.86 (Fig. 1). All genotypes belonging to subsp hypogaea (including var. hirsuta and var. hypogaea ) except 'Shengxian Xiaohongmao' (belonging to var hirsuta) were grouped together (referred as 'subsp. hypogaea group'), and all genotypes of subsp. fastigiata including var. fastigiata and var. vulgaris were clustered in another group (referred as 'subsp. fastigiata group'). The genotypes of the subsp. hypogaea group were all landraces including 15 resistant genotypes and one susceptible genotype, and could be further divided into 3 sub- 
Table 4 Polymorphic information among 31 peanut genotypes as revealed by AFLP analysis

\begin{tabular}{|c|c|c|c|c|c|c|c|}
\hline Primer & Polymorphic loci & Primer & Polymorphic loci & Primer & Polymorphic loci & Primer & Polymorphic loci \\
\hline P1M58 & 2 & P3M59 & 1 & P8M52 & 4 & P9M52 & 2 \\
\hline P1M61 & 3 & P3M60 & 2 & P8M53 & 3 & P9M57 & 1 \\
\hline P1M47 & 4 & P3M61 & 1 & P8M54 & 3 & P9M61 & 1 \\
\hline P1M48 & 1 & P4M47 & 3 & P8M55 & 1 & P13M50 & 2 \\
\hline P1M62 & 5 & P4M55 & 2 & P8M56 & 3 & P13M51 & 1 \\
\hline P2M47 & 2 & P5M48 & 2 & P8M57 & 1 & Total & 72 \\
\hline P2M48 & 2 & P5M53 & 1 & P8M60 & 1 & & \\
\hline P3M52 & 3 & P7M55 & 1 & P9M48 & 2 & & \\
\hline P3M58 & 3 & P8M47 & 3 & P9M51 & 6 & & \\
\hline
\end{tabular}

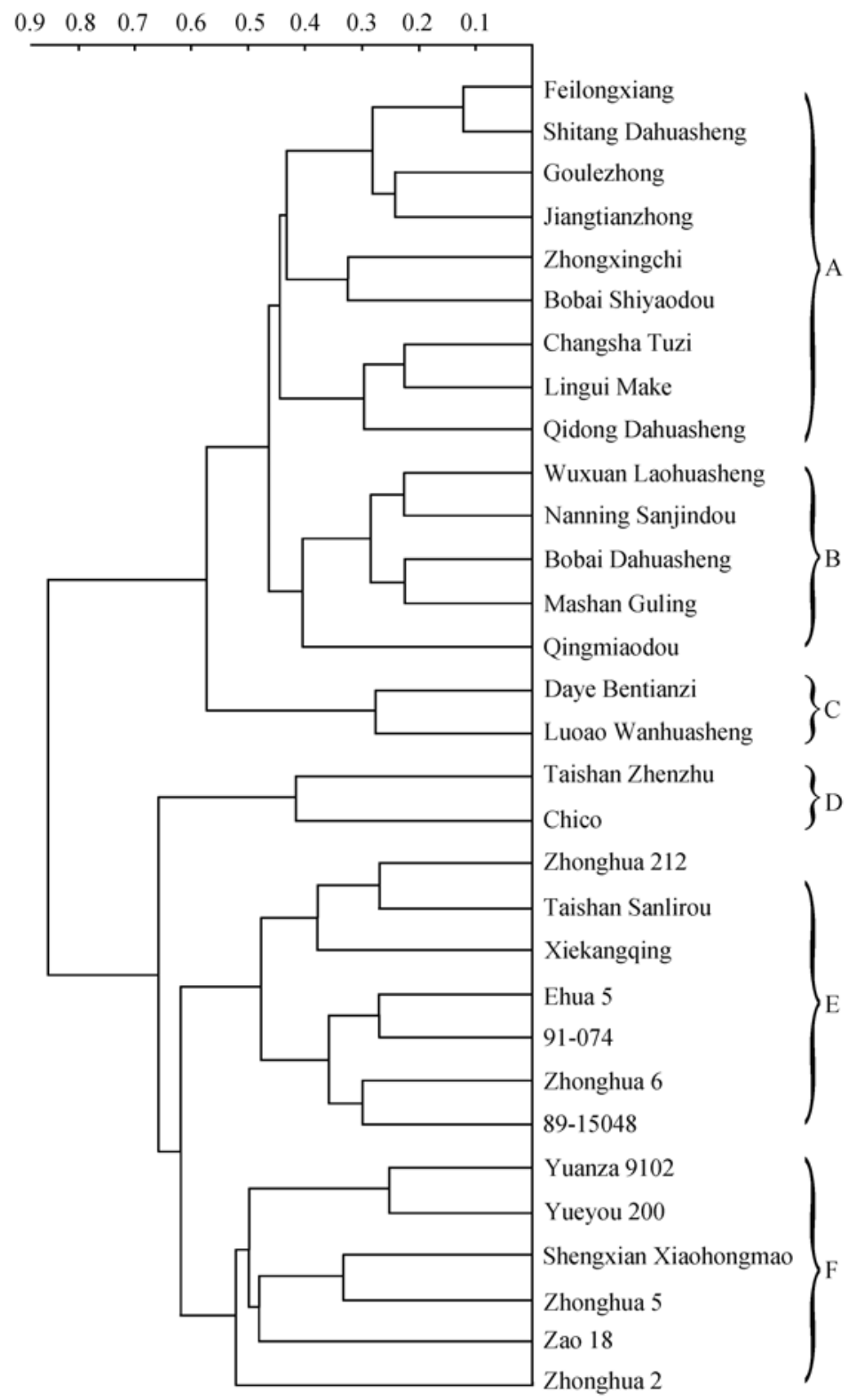

Fig. 1 Dendrogram of 31 peanut genotypes by SSR data analysis 
groups at the genetic distance of 0.47 (subgroup A, B, and C). Subgroup A consist of 9 resistant genotypes including 7 hirsuta genotypes and 2 hypogaea genotypes. Two var. hypogaea genotypes, 'Goulezhong' and 'Jiangtianzhong', were grouped into the same sub-subgroup. Two var hirsuta genotypes from Hunan Province, 'Changsha Tuzi' and 'Qidong Dahuasheng', were also grouped into a sub-sub-group. Sub-group B included 5 var hirsuta genotypes with BW resistance. Sub-group C consisted of 2 var. hirsuta genotypes from Jiangxi Province, the BW-susceptible 'Daye Bentianzi' and the BW-resistant 'Luoao Wanhuasheng'. The genetic variation in sub-group A was greater than in sub-group B and sub-group C.

The subsp. fastigiata group, included all the genotypes belonging to subsp. fastigiata except a var hirsuta landrace, 'Shengxian Xiaohongmao'. This group consisting of 12 resistant and 3 susceptible genotypes could be further divided into 3 sub-groups (sub-group D, E, and F) at the genetic distance of 0.61 . Therefore, the variation in this group was wider than that in the subsp. hypogaea group. Sub-group D included 2 var. vulgairs genotypes, the resistant landrace 'Taishan Zhenzhu' and the susceptible line 'Chico'. Sub-group E consisted of 7 resistant genotypes; Zhonghua 212, 89-15048, and their common resistant parent 'Taishan Sanlirou'; 'Ehua 5' and its reistant donor 'Xiekangqing' were grouped into this sub-group. Sub-group $F$ consisted of 'Shengxian Xiaohongmao' and 5 improved breeding lines belonging to var vulgaris, of which, 3 were resistant and 2 susceptible to BW. In this sub-group, BW-susceptible 'Zhonghua 5' and BW-resistant 'Zhonghua 2' had a common susceptible parent 'Ehua 4'. 'Zhonghua 2' however had another resistant parent 'Xiekangqing'.

\subsection{Genetic diversity based on AFLP analysis}

One hundred and twenty-six randomly selected Pst I /Mse I primer combinations were used to amplify the DNA of the 31 peanut genotypes. Thirty-two combinations detected polymorphic DNA bands, each of these amplified 1 to 6 polymorphic loci, generating a total of 72 polymorphic bands with an average of 2.25 loci per primer (Table 4). Primer P9M51 amplified 6 polymorphic loci, and could group the 31 genotypes into 11 clusters and identify 5 unique genotypes among the 31 accessions. Primer P1M62 could amplify 5 polymorphic loci, and could classify the 31 genotypes into 11 clusters and identify 9 unique genotypes.

Based on AFLP analysis, the highest and the lowest pairwise distances among the 31 genotypes were 0.57 and 0.06 , respectively, with an average distance of 0.25 . There were 6 genotype pairs with distances over 0.5. In the dendrogram based on AFLP data (Fig. 2), the BW-susceptible var. vulgaris genotype, 'Chico' introduced from ICRISAT, was highly different from all other genotypes tested and was as such placed in a unique group. The other 30 genotypes, all of which originated from China, were divided into two groups at the genetic distance of 0.41 , with all subsp. hypogaea genotypes (except 'Shengxian Xiaohongmao') in the first group (referred as 'subsp. hypogaea group') and most subsp. fastigiata genotypes in the second group (referred as 'subsp. fastigiata group'). The breeding lines 'Zao 18', 'Yueyou 200', and 'Ehua 5' belonging to var. vulgaris were in the subsp. hypogaea group. The first group consisting of 14 var. hirsuta, 2 var. hypogaea, and 3 var. vulgaris genotypes was further divided into 3 sub-groups (A, B, and C). In sub-group A, all five genotypes were $\mathrm{BW}$-resistant landraces belonging to var. hirsuta. Sub-group B consisted of 2 var. vulgaris, 1 var. hypogaea, and 8 var. hirsuta genotypes. Among the 11 genotypes, 9 were resistant and 2 were susceptible to BW ('Zao 18' and 'Daye Bentianzi'). Sub-group C consisted of 1 var. hypogaea, 1 var. hirsuta landrace, and 1 advanced breeding line, 'Ehua 5'. All these genotypes were BW-resistant.

The second group was comprised of 11 genotypes including a susceptible line. Among these, 1 was the var. hirsuta genotype and the other 10 were subsp. fastigiata. The genetic diversity in this group was greater than that in the first group. Two resistant 


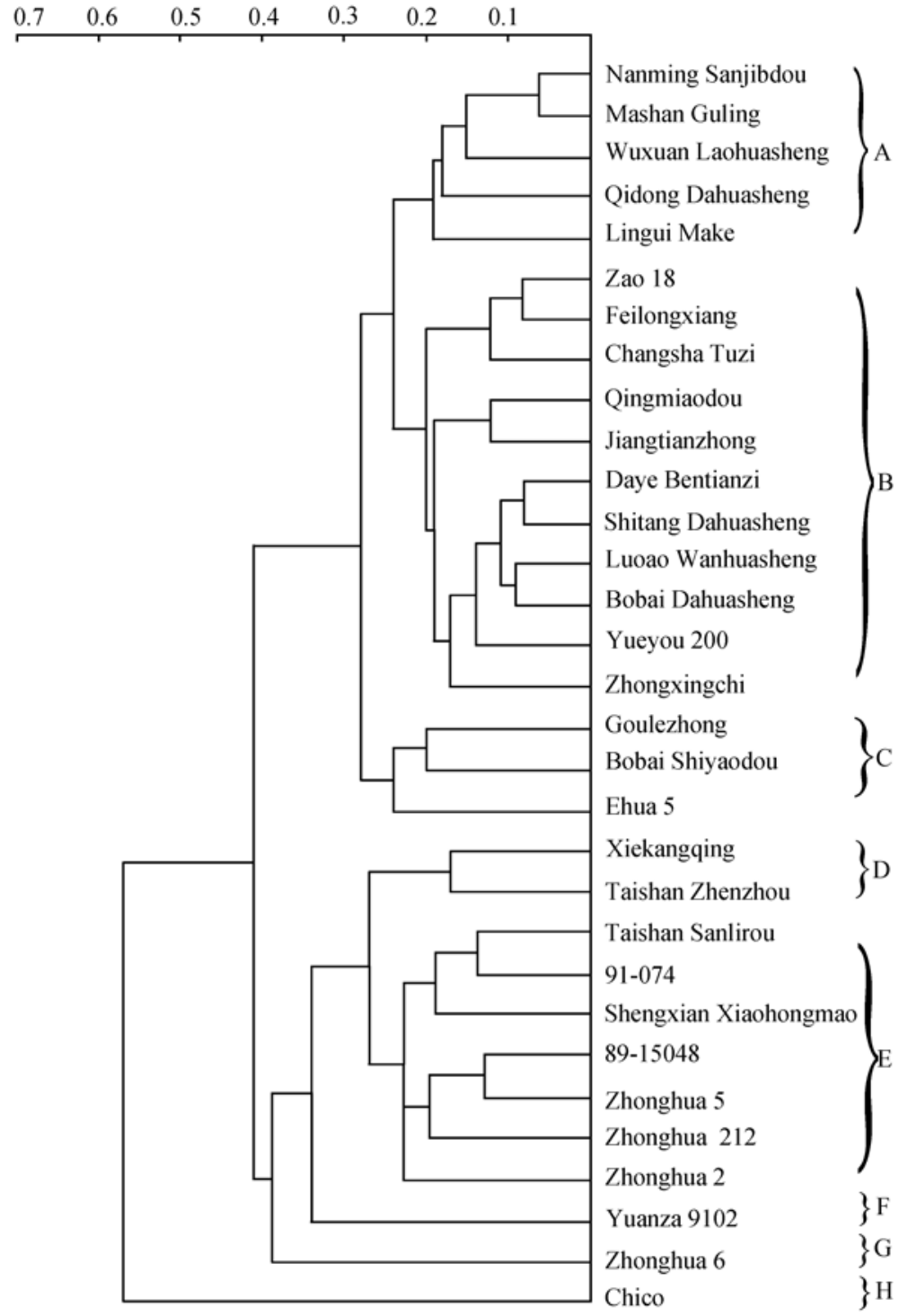

Fig. 2 Dendrogram of 31 peanut genotypes by AFLP data analysis

breeding lines, 'Yuanza 9102' and 'Zhonghua 6', were different from the other 9 genotypes and were grouped into two unique sub-groups ( $F$ and $G$ ), respectively. The remaining 9 genotypes were divided into two sub-groups (D and E). Sub-group D consisted of 2 var. vulgaris resistant landraces ('Xiekangqing' and 'Taishan Zhenzhu'), which have been extensively used in the previous breeding programs in China. In sub-group E, 'Shengxian Xiaohongmao' with BW resistance is a var. hirsuta line and 'Zhonghua 5' is a BW-susceptible breeding line belonging to var. vulgaris. The other four BW-resistant breeding lines, '91-074', '89-15048', 'Zhonghua 212', and 'Zhonghua 2', all having 'Taishan Sanlirou' as the resistant donor in their pedigrees, were all clustered in the same sub-group.

\subsection{Relationship and diversity of peanut based on SSR together with AFLP analysis}

Based on a combined analysis of SSR and AFLP data, the 31 peanut genotypes with bacterial wilt resistance were divided into two main groups (dendrogram 
not shown). All subsp. hypogaea genotypes, except the hirsuta variety 'Shengxian Xiaohongmao', were clustered together in a group, which also contained $3 \mathrm{vul}$ garis varieties. The remaining 11 subsp. fastigiata varieties and one hirsuta genotype 'Shengxian Xiaohongmao' were placed in another group. The subsp. hypogaea group could be divided into four sub-groups and the two hypogaea genotypes, 'Goulezhong' and 'Jiangtianzhong' were divided into different subgroups. The subsp. fastigiata group could be divided into five subgroups. 'Chico' and 'Zhonghua 6' were different from the other genotypes in this group and formed two unique subgroups. The clustering based on the combined analysis of SSR and AFLP data was broadly similar to that generated based on either individual dataset.

\section{Discussion}

Bacterial wilt is a serious disease for peanut in certain regions in the world and genetic enhancement for resistance is important for sustainable development of peanut production in these disease-prone areas. More efforts are required to improve peanut cultivars by integration of BW resistance with other desirable agronomic characteristics. Better understanding of the genetic diversity of BW-resistant peanut germplasm is crucial for various reasons. Although the cultivated peanut germplasm exhibits a high level of morphological variation, the detectable level of DNA polymorphism in this species is relatively low when compared to other crops ${ }^{[19,22-24]}$. Since He and Prakash (1997) ${ }^{[11]}$ reported that there was considerable DNA polymorphism in A. hypogaea as revealed by the AFLP approach, this assay has been used for molecular diversity studies in peanut by several researchers ${ }^{[8-18,25-28]}$. In the present study, both SSR and AFLP approaches detected acceptable levels of molecular diversity among the peanut lines with various levels of resistance to bacterial wilt, although some primers were more efficient than others.

Based on the SSR and AFLP analyses, genetic diversity among the peanut genotypes was verified at the molecular level. The diversity detected by SSR markers was greater than that observed through AFLP profiles. In the dendrogram based on SSR analysis (Fig. 1), all genotypes belonging to subsp. fastigiata including var. vulgaris and var. fastigiata were grouped together, and those belonging to subsp. hypogaea including var. hypogaea and var. hirsuta were classified into another group with the exception of ‘Shengxian Xiaohongmao'.

The clustering of peanut genotypes based on SSR data and AFLP data were similar (Figs. 1 and 2), although the SSR clustering was more comparable to the current classification system based on morphological characteristics. Thus, the SSR approach may be more efficient for peanut. In the dendrogram based on AFLP analysis, several breeding lines, i.e. Zao 18, Yueyou 200, and Ehua 5, were grouped into the subsp hypogaea group (Fig. 2) even though these belonged to subsp fastigiata. It is interesting to note that these three breeding lines had direct or indirect parents belonging to subsp hypogaea ${ }^{[29]}$, and there was no landrace of subsp fastigiata in the subsp hypogaea group (Fig. 2). Thus, it is possible that the AFLP approach can trace the genomic introgression among the subspecies or botanic varieties. Another var. hirsuta genotype 'Shengxian Xiaohongmao' was in the subsp fastigiata group in both SSR and AFLP based dendrograms. This genotype is morphologically different from most other var. hirsuta landraces particularly in a shorter growth period and less reticulated pods. Natural genomic introgression from subsp. fastigiata may have occurred during the evolution of this genotype, and its classification will be re-considered.

The frequency of BW-resistant germplasm accessions in different botanic types of A. hypogaea is different. The var. hirsuta (also known as dragon type) widely cultivated in China for hundreds of years before other botanical varieties were introduced ${ }^{[29]}$, has the highest frequency of BW-resistant accessions. Among the 315 var. hirsuta lines collected, 68 have been identified as highly BW-resistant ${ }^{[6,7]}$, indicating 
that var. hirsuta is an important source of BW resistance. One objective of investigating the genetic diversity of BW-resistant germplasm lines is to identify suitable genotypes for developing mapping population(s) and new cultivars. Based on the study, var. hirsuta resistant lines such as 'Lingui Make' and 'Feilongxiang' and var. vulgaris line 'Taishan Zhenzhu' are recommended as parents in crosses with the BW-susceptible breeding such as 'Zhonghua 5' with high yield, high seed oil content, and early maturity.

\section{References}

1 Liao BS, Duan NX, Wang YY, Sun DR, Mehan VK. Host-plant resistance to groundnut bacterial wilt: genetic diversity and enhancement. In: Groundnut bacterial wilt in Asia: proceedings of the Third Working Group Meeting, Wuhan, China. Mehan VK, MeDonald D (eds). ICRISAT, Patancheru, India. 1994, 91-96.

2 Liang XQ. Present status of groundnut bacterial wilt in south China. In: Groundnut bacterial wilt: proceedings of the Fourth Working Group Meeting, Vietnam Agricultural Science Institute, Hanoi, Vietnam. Pande S, Liao BS, Hong NX, Johansen C, Gowda CLL, eds. International Crops Research Institute for the Semi-Arid Tropics, India. 1998, 23-26.

3 Liao BS, Duan NX, Jiang HF, Liang XQ, Gao GQ. Germplasm screening and breeding for resistance to bacterial wilt in China. In: Groundnut bacterial wilt: proceedings of the Fourth Working Group Meeting, Vietnam Agricultural Science Institute, Hanoi, Vietnam. Pande S, Liao BS, Hong NX, Johansen C, Gowda CLL, eds. International Crops Research Institute for the Semi-Arid Tropics, India. 1998, 75-81.

4 Duan NX, Tan YJ, Jiang HF, Hu DH. Screening groundnut germplasm for resistance to bacterial wilt. Oil Crops of China, 1993, 15 (1): 22-25 (in Chinese with an English abstract).

5 Liao BS. A broad review and perspectives on breeding for resistance to bacterial wilt. In: Bacterial wilt disease and the Ralstonia solanacearum species complex. Allen C, Prior P, Hayward AC, eds. The American Phytopathological Society. 2005, 225-238.

6 Liao BS, Liang XQ, Jiang HF, Lei Y, Shan ZH, Zhang XY. Progress on genetic enhancement for resistance to groundnut bacterial wilt in China. In: Bacterial wilt disease and the Ralstonia solanacearum species complex. Allen C, Prior P, Hayward AC, eds. The American Phytopathological Society. 2005, 239-246.

7 Jiang HF, Duan NX, Ren XP. Evaluation of groundnut germplasm. Chinese Journal of Oil Crop Science, 1998, 20(3): 31-35 (in Chinese with an English abstract).
8 Dwivedi SL, Gurtu S, Chandra S, Yuejin W, Nigam SN. Assessment of genetic diversity among selected groundnut germplasm. I: RAPD analysis. Plant Breed, 2001, 120(4): 345-349.

9 Ferguson ME, Burow MD, Schulze SR, Bramel PJ, Paterson AH, Kresovich S, Mitchell S. Microsatellite identification and characterization in peanut (A. hypogaea L.). Theor Appl Genet, 2004, 108(6): 1064-1070.

10 Ferguson ME, Bramel PJ, Chandra S. Gene diversity among botanical varieties in peanut (Arachis hypogaea L.). Crop Sci, 2004, 44(5): 1847-1854.

11 He GH, Prakash CS. Identification of polymorphic DNA markers in cultivated peanut (Arachis hypogaea L.). Euphytica, 1997, 97(2): 143-149.

12 He GH, Prakash CS. Evaluation of genetic relationships among botanical varieties of cultivated peanut (Arachis hypogaea L.) using AFLP markers. Genet Resour Crop Evol, 2001, 48(4): 347-352.

13 He G, Meng RH, Newman M, Gao GQ, Pittman R N, Prakash C S. Microsatellites as DNA markers in cultivated peanut (Arachis hypogaea L). BMC Plant Biol, 2003, 3(3): 1-6.

14 Hopkins M S, Casa A M, Wang T, Mitchell S E, Dean R E, Kochert G D, Kresovich S. Discovery and characterization of polymorphic simple sequence repeats (SSRs) in peanut. Crop Sci, 1999, 39(4): 1243-1247.

15 Jiang HF, Ren XP. RAPD analysis in cultivated groundnut (Arachis hypogaea L.). Journal of Peanut Science, 2002, 31(2): 10-13 (in Chinese with an English abstract).

16 Weng YJ, Santosh G, Nigam SN. Fingerprints in groundnutusing AFLP. Chinese Journal of Oil Crops Science, 1999, 21(2): 10-12 (in Chinese with an English abstract).

17 Ye BY, Chen YQ, Zhu JM. Analysis of genetic relationship among peanut cultivars (Arachis hypogaea L.). Chinese Journal of Oil Crops Science, 1999, 21(3): 15-18 (in Chinese with an English abstract).

18 Upadhyaya HD, Bramel PJ, Ortiz R, Singh S. Geographical patterns of diversity for morphological and agronomic traits in the groundnut germplasm collection. Euphytica, 2002, 128(2): 191-204.

19 Kochert GD, Halward T, Branch WD, Simpson CE. RFLP variability in peanut (Arachis hypogaea L.) cultivars and wild species. Theor Appl Genet, 1991, 8(5): 565-570.

20 Vos P, Hogers R, Bleeker M, Reijans M, Lee van de T, Hornes M, Frijters A, Pot J, Peleman J, Kuiper M, Zabeau M. AFLP: A new technique for DNA fingerprinting. Nucleic Acids Res, 1995, 23(21): 4407-4414.

21 Nei M, Li W. Mathematical model for studying genetic variation in terms of restriction endonucleases. Proc Natl Acad Sci USA, 1979, 76(10): 569-573.

22 Halward T, Stalker HT, Lerue E, Kochert G. Genetic variation detectable with molecular markers among unadapted germplasm resources of cultivated peanut and related wild species. 
Genome, 1991, 34(6): 1013-1020.

23 Halward T, Stalker HT, LeRue E, Kochert GD. Use of single primer DNA amplification in genetic studies of peanut (Arachis hypogaea L.). Plant Mol Biol, 1992, 18(2): 315-325.

24 Paik-Ro OG, Smith RL, Kochert DA. Restriction fragment length polymorphism evaluation of six peanut species within the Arachis section. Theor Appl Genet, 1992, 84(1-2): 201-208.

25 Subramanian V, Gurtu S, Nageswara Rao RC, Nigam SN. Identification of DNA polymorphism in cultivated groundnut using random amplified polymorphic DNA (RAPD) assay. Genome, 2000, 43(4): 656-660.

26 Raina SN, Rani V, Kojima T, Ogihara Y, Singh KP, Devarumath RM. RAPD and ISSR fingerprints as useful genetic markers for analysis of genetic diversity, varietal dentification, and phylogenetic relationships in peanut (Arachis hypogaea L.) cultivars and wild species. Genome, 2001, 44(5): 763-772.

27 Tang RH, He LQ, Gao GQ, Zhuang WJ, Han ZQ, Zhong RC. Simple sequence repeats molecular markers in peanut botanical variety 'fastigiata' in A hypogaea L. Journal of Peanut Science, 2004, 33(2): 11-16 (in Chinese with an English abstract).

28 Tang RH, Zhuang WJ, Gao GQ, Han ZQ, Zhong RC, He LQ, Zhou CQ. Simple sequence repeats polymorphism among accessions of var. vulgaris Harz in Arachis hypogaea L. Chinese Journal of Oil Crops Science, 2004, 26(2): 20-26 (in Chinese with an English abstract).

29 Sun DR. Breeding of Groundnut. Beijing: China Agricultural Press, 1998(in Chinese)

\section{用 SSR 和 AFLP 技术分析花生抗青枯病种质遗传多样性的比较}

姜慧芳 ${ }^{1,2}$, 廖伯寿, 任小平 ${ }^{1}$, 雷 永 $^{1}$, Emma Mace $^{3}$, 傅廷栋 ${ }^{2}$, J. H. Crouch $^{3}$

1. 中国农业科学院油料作物研究所, 武汉 430062;

2. 华中农业大学植物科学技术学院, 武汉 430070;

3. 国际热带半干旱地区作物研究所, A. P. 502324, 印度

摘 要: 由 Ralstonia solanacearum E. F. Smith 引起的青枯病是若干亚洲和非洲国家花生生产的重要限制因子, 利用抗病品种 是防治这一病害最好的措施。虽然一大批抗青枯病花生种质资源材料已被鉴定出来, 但对其遗传多样性没有足够的研究, 限 制了在育种中的有效利用。本研究以 31 份对青枯病具有不同抗性的栽培种花生种质为材料, 通过简单序列重复(SSR)和扩 增片段长度多态性(AFLP)技术分析了它们的遗传多样性。通过 78 对 SSR 引物和 126 对 AFLP 引物的鉴定, 篮选出能显示 抗青枯病种质多态性的 SSR 引物 29 对和 AFLP 引物 32 对。所选用的 29 对多态性 SSR 引物共扩增 91 条多态性带, 平均每 对引物扩增 3.14 条多态性带; 32 对多态性 AFLP 引物共扩增 72 条多态性带, 平均扩增 2.25 条多态性带。在所笁选引物中, 4 对 SSR 引物(14H06, 7G02, 3A8, 16C6)和 1 对 AFLP 引物(P1M62)检测花生多态性的效果优于其他引物。SSR 分析获得的 31 个花生种质的遗传距离为 0.12-0.94, 平均为 0.53 , 而 AFLP 分析获得的遗传距离为 $0.06 \sim 0.57$, 平均为 0.25 , 基于 SSR 分析 的遗传距离大于基于 AFLP 分析的遗传距离, 疏枝亚种组的遗传分化相对大于密枝亚种组。基于两种分析方法所获得的聚 类结果基本一致, 但 SSR 数据聚类结果与栽培种花生的形态分类系统更为吻合。根据分析结果, 对构建青枯病抗性遗传图 谱群体的核心亲本和抗性育种策略提出了建议。

关键词: 花生; 抗青枯病种质; 遗传多样性; SSR; AFLP

作者简介：姜慧芳(1963-)，女，湖北新洲人，博士，研究方向：花生种质资源及生物技术研究。E-mail: peanutlab@oilcrops.cn 